Genetic Epidemiology 15:391-401 (1998)

\title{
Segregation Analysis of Cutaneous Melanoma in Queensland
}

\author{
Joanne F. Aitken, ${ }^{1 *}$ Joan Bailey-Wilson, ${ }^{2}$ Adèle C. Green, ${ }^{1}$ \\ Robert MacLennan, ${ }^{1}$ and Nicholas G. Martin ${ }^{1}$ \\ ${ }^{1}$ Queensland Institute of Medical Research, Brisbane, Australia \\ ${ }^{2}$ National Human Genome Research Institute, National Institutes of Health, \\ Baltimore, Maryland
}

To investigate whether the familial clustering of cutaneous melanoma is consistent with Mendelian inheritance of a major autosomal gene, maximum likelihood segregation analyses were performed in a population-based sample of 1,912 families ascertained through a proband with melanoma diagnosed in Queensland between 1982 and 1990. Analyses were performed with the S.A.G.E. statistical package, using the REGTL program for a binary trait with a variable age of onset. We sought medical confirmation for all family members reported to have had melanoma, and only medically verified cases among relatives were included in the analyses. The hypothesis of codominant Mendelian inheritance gave a significantly better fit to the data than either dominant or recessive Mendelian inheritance, or environmental transmission. Overall, both Mendelian inheritance of a single major gene, and purely environmental transmission were rejected $(P$ $<0.001)$. In both the single major gene and environmental models, there was strong evidence of familial dependence in melanoma occurrence $(P<0.001)$. These results are consistent with reported genetic heterogeneity in melanoma inheritance and suggest that other familial factors, such as pigmentation, skin type, and sun exposure habits, may play an important role in the familial clustering of melanoma. Genet. Epidemiol. 15:391-401, 1998. @ 1998 Wiley-Liss, Inc.

Key words: skin neoplasms; genetics; family characteristics; heterogeneity

\section{INTRODUCTION}

The incidence of malignant melanoma is increasing in white-skinned populations throughout the world and has more than doubled in Queensland, Australia,

\footnotetext{
*Correspondence to: Dr. Joanne F. Aitken, Queensland Institute of Medical Research, Post Office Royal Brisbane Hospital, Queensland 4029, Australia.
}

Received 6 February 1997; Revised 25 August 1997; Accepted 30 August 1997

(C) 1998 Wiley-Liss, Inc. 


\section{$392 \quad$ Aitken et al.}

since 1980. In 1987, the age-adjusted incidence of invasive melanoma was 48.9 per 100,000 for men and 39.7 per 100,000 for women [MacLennan et al., 1992]. This is the highest incidence of melanoma in the world and the highest incidence of any cancer in Queensland, with the exception of nonmelanoma skin cancer.

Approximately $10 \%$ of melanoma cases in Queensland have one or more firstdegree relatives with melanoma, and population-based case-control and family studies suggest that a positive family history is associated with a two- to threefold increased melanoma risk [Wallace et al., 1971; Holman et al., 1984; Green et al., 1986; Aitken et al., 1994]. The familial clustering of melanoma may be due to the inheritance of melanoma susceptibility genes, or to correlation between family members in known melanoma risk factors [Hopper and Carlin, 1992], such as propensity to develop melanocytic nevi, skin type, and sun exposure, the most important environmental determinant [IARC, 1992].

A gene (CDKN2A) that encodes the low-molecular-weight protein $\mathrm{p} 16^{\mathrm{ink} 4 \mathrm{~A}}$ has been identified in the same interval on chromosome 9p21, which had previously been mapped to familial melanoma [Cannon-Albright et al., 1992; Kamb et al., 1994a]. The p16 ${ }^{\text {ink4A }}$ protein inhibits cyclin-dependent kinases 4 and 6 (CDK4 and CDK6), which are involved in the stimulation of cell division. Germline CDKN2A mutations have been detected with varying frequencies in small samples of Australian, Dutch, and North American families selected because of their high risk of melanoma [Hussussian et al., 1994; Kamb et al., 1994b; Walker et al., 1995; Gruis et al., 1995]. The frequency of CDKN2A mutations in the population is unknown, although a recent observation that only $7.8 \%$ of 64 Swedish melanoma-prone kindreds with multiple dysplastic nevi carry a germline CDKN2A mutation suggests that this gene probably accounts for only a fraction of familial melanoma [Platz et al., 1997]. Predisposition to melanoma has been linked to markers on chromosome 1p [Goldstein et al., 1993, 1996] and 6p [Walker et al., 1994], although again the importance of these genes in melanoma aetiology in the general population is unknown. To investigate whether the familial clustering of melanoma can be explained by Mendelian inheritance of a major susceptibility gene, segregation analyses were performed in a population-based sample of 1,912 Queensland families ascertained through a proband with melanoma diagnosed in Queensland between 1982 and 1990.

\section{METHODS \\ Study Subjects}

Family ascertainment and data collection have been described in detail previously [Aitken et al., 1996a]. Briefly, we ascertained all 12,006 first incident cases of cutaneous melanoma (invasive and in situ) diagnosed in Queensland residents between 1982 and 1990 and reported to the Queensland Cancer Registry, or found by comparing cancer registrations for 1984 and 1987 with records of pathology laboratories throughout Queensland. From this exercise, we estimate that registry records are $\sim 95 \%$ complete for the study period. Doctor's permission was obtained to approach 10,407 cases, of whom 7,784 (75\%) returned a brief family history question-

naire, stating whether any of their first-degree relatives (parents, siblings, children) had had a diagnosis of melanoma. A total of 2,920 probands was sampled from these respondents, including all who had claimed a positive family history $(\mathrm{n}=1,529)$ and 
an approximate $20 \%$ random sample of the remainder $(n=1,391)$. Probands were sent a detailed family history questionnaire, asking for the names and addresses of all first-degree relatives, relatives' vital status, dates of birth, and ages, and whether any of these relatives had had a melanoma diagnosed by a doctor. To avoid bias in determining the mode of inheritance, second and lower degree relatives were enrolled in the study according to a sequential sampling scheme [Cannings and Thompson, 1977]; first-degree relatives of all relatives with confirmed melanoma were ascertained through the detailed family history questionnaire, described above, which was mailed to all confirmed positive relatives. In total, 15,989 relatives belonging to 1,912 separate families were reported by $2,118(73 \%)$ probands or other positive relatives. A total of 1,044 relatives for whom date of birth was unknown was excluded, leaving 14,945 relatives for analysis. There were 188 families independently ascertained through two or more probands; to avoid ascertainment bias, these families were included in the dataset separately for each proband in the family.

\section{Confirmation of Melanomas Among Relatives}

We sought medical confirmation and dates of diagnosis for the total 1,348 relatives reported by probands or other relatives to have had melanoma [Aitken et al., 1996b]. Access to medical records was refused by 71 relatives or their next-of-kin, and records could not be located for 181 relatives. Of the remaining 1,096 relatives, medical confirmation of melanoma as the diagnosis was obtained for 650 (59.3\%). Most false positive reports proved to be basal or squamous cell carcinoma, solar keratoses, or benign nevi, which are far more common and are often excised from the skin [Aitken et al., 1996b]. Only the 650 medically verified cases among relatives were included in the segregation analyses. All other relatives were treated as unaffected.

\section{Statistical Methods}

Evidence for melanoma inheritance was assessed with the statistical package S.A.G.E. [1992], using the REGTL program for segregation analysis of binary traits with a variable age of onset under the class A regressive logistic model [Bonney, 1986]. This model assumes that the affection status of an individual's parents completely explains any additional familial dependence, either genetic or environmental, which remains after accounting for Mendelian inheritance of a major gene. In other words, after accounting for Mendelian inheritance and the parents' phenotypes, it is assumed that no additional information about an individual's probability of developing melanoma is obtained from the phenotypes of siblings. Mendelian inheritance, if it exists, is assumed to be through a single autosomal locus with two alleles, giving three possible genotypes (AA, AB, and $\mathrm{BB}$ ), where allele $\mathrm{A}$ is associated with melanoma susceptibility. The program utilizes standard methods of ascertainment correction by conditioning the likelihood of each pedigree on the probands' phenotype and age at onset of melanoma.

The calculation of the likelihood for family data is described by Elston and Stewart (1971). Briefly, the likelihood is a function of the population frequencies of the three genotypes $\left(\psi_{\mathrm{AA}}, \psi_{\mathrm{AB}}\right.$, and $\left.\psi_{\mathrm{BB}}\right)$ (determined by the population frequency of allele $\mathrm{A}, \mathrm{q}_{\mathrm{A}}$, assuming Hardy-Weinberg equilibrium); the transmission probabilities of the three genotypes $\left(\tau_{\mathrm{AA}}, \tau_{\mathrm{AB}}\right.$, and $\left.\tau_{\mathrm{BB}}\right)$, where $\tau_{\mathrm{AA}}$, for example, is the probability 


\section{$394 \quad$ Aitken et al.}

that a parent of genotype AA will transmit allele A to their child; susceptibility $\gamma$, defined as the probability that an individual selected at random from the population will develop melanoma by age infinity [Go et al., 1993] (this will be $<1.0$ if, for example, environmental factors to which only a portion of the population is ever exposed are necessary for the development of disease); and the cumulative probability that an individual of a particular genotype will develop melanoma by a given age. This last was modelled using a logistic function that includes a baseline parameter $\beta$, a coefficient $\alpha$ for age, and separate coefficients $\left(\delta_{\text {parent unaffected }}\right.$ and $\left.\delta_{\text {parent affected }}\right)$ for the affection status of each parent [Bonney, 1986]. These coefficients were assumed to be the same for the father and mother. The baseline parameter $\beta$ may vary according to genotype and was assumed to be the same for both sexes, given that the age of onset distributions were similar for men and women in this sample. Susceptibility $\gamma$ was assumed to be the same for all three genotypes and both sexes. This model was chosen over one in which susceptibility is genotype-dependent and the baseline parameter is not, as there is epidemiologic evidence that patients with a family history have an earlier average age of onset than do sporadic cases, particularly for variably sun-exposed sites such as the trunk and legs [Aitken et al., 1996a].

We fit two groups of models to the data: the first group assumed no familial correlation in addition to that explained by Mendelian inheritance (i.e., $\delta_{\text {parent unaffected }}$ and $\delta_{\text {parent affected }}$ were fixed at 0 ), whereas the second allowed for additional familial correlation. Within each group, we tested six models: Mendelian transmission of a single dominant allele; Mendelian transmission of a single recessive allele; Mendelian transmission of a codominant allele; no parent-offspring transmission (the environmental hypothesis) with two age-of-onset distributions in the population; no parent-offspring transmission with three age-of-onset distributions; and the "no major type" model, which assumes there is only one underlying age-of-onset distribution in the population, any variation from expectation being entirely random.

Mendelian transmission corresponds to the case in which $\tau_{\mathrm{AA}}=1.0, \tau_{\mathrm{AB}}=0.5$, and $\tau_{\mathrm{BB}}=0$. In the dominant inheritance model, two age-of-onset distributions are assumed: one for genotypes $\mathrm{AA}$ and $\mathrm{AB}$ and another for $\mathrm{BB}$. The recessive inheritance model also has two age-of-onset distributions, one for $\mathrm{AA}$, and another for $\mathrm{AB}$ and $\mathrm{BB}$, whereas the codominant model assumes three different age-of-onset distributions, one for each genotype. In the case of no parent-offspring transmission, $\tau_{\mathrm{AA}}=$ $\tau_{\mathrm{AB}}=\tau_{\mathrm{BB}}$. In a population at equilibrium and assuming complete correction for the mode of ascertainment, $\tau$ and $\mathrm{q}_{\mathrm{A}}$ are expected to be equal under this model [Bailey-Wilson et al., 1986]. However, they were allowed to differ here because the two-step method of sampling that we used made complete ascertainment correction problematic.

Parameters were estimated using the method of maximum likelihood, using up to 18 sets of starting values for each model to ensure that the likelihood surface was thoroughly examined. The maximum likelihood under each model was compared to that under a full model - in which all of the parameters in the likelihood function were estimated without restriction-by the likelihood ratio test [Kleinbaum et al., 1982] to assess whether the model of interest provided an adequate fit to the data. Cumulative incidence to 100 years, i.e., the expected probability that an individual selected at random from the population will develop melanoma by 100 years of age, was calculated for each model by extrapolating from the parametric survival curve using the estimated parameter values for that model [S.A.G.E., 1992]. 


\section{Adjustment for Sampling Scheme}

As our sample was weighted by self-reported positive history families in the ratio of 5:1, negative history families were weighted by a factor of five in the analysis to return the sample to correct population proportions. This "population sample" allowed us to estimate correctly the population gene frequency $\mathrm{q}_{\mathrm{A}}$, but provided smaller standard errors and a smaller likelihood than would otherwise have been the case. Therefore, to obtain correct likelihoods, all models were re-run using the actual sample while fixing all maximum likelihood estimates of the parameters to the values obtained from the weighted "population sample."

\section{RESULTS}

Of the total 1,912 families, 509 had at least one member with cutaneous melanoma in addition to the proband: 415 families had one affected member in addition to the proband, 67 families had two, 20 families had three, and seven families had four or more. The distribution of melanomas according to family size has been presented elsewhere [Aitken et al., 1996a]. The average age of onset of melanoma was similar for male $(49.9 \mathrm{yr}$; $95 \% \mathrm{CI}$ : $48.8,51.2)$ and female relatives $(45.9 \mathrm{yr} ; 95 \% \mathrm{CI}$ : $43.8,48.0)$.

\section{Segregation Analysis}

The results of the segregation analyses are presented in Table I for the group of models (group A) in which we assumed no familial dependence in addition to that explained by a major gene and in Table II for the group of models (group B) that included terms for additional familial dependence. In both groups of models, the "no major type" hypothesis gave a significantly worse fit to the data than either the genetic or environmental hypotheses, implying the existence of more than one ageof-onset distribution in the population. By comparing the likelihoods for the group A genetic models, codominant Mendelian inheritance provided a significantly better fit to the data than either dominant or recessive inheritance (e.g., for the dominant versus codominant models, $\chi^{2}{ }_{1}=180.11, P<0.001$ ), although both the codominant and environmental models were rejected in favour of the full model $(P$ $<0.001)$ (Table I).

The inclusion in group B models of logistic regression terms for familial dependence in addition to a major gene significantly improved the fit of all models $(P<0.001)$ (Table II). Codominant Mendelian inheritance provided a significantly better fit to the data than either dominant or recessive inheritance and also provided a significantly better fit than either of the environmental models. However, codominant inheritance was rejected in favour of the full model $(P<0.001)$. (We were unable to achieve convergence of the parameter estimates for the full model in Table II, although had this been obtained, the likelihood would have been even greater than that shown, and the codominant Mendelian model would have been even more strongly rejected.)

\section{DISCUSSION}

Using complex segregation analysis, we have found no evidence of Mendelian inheritance of cutaneous melanoma through a single major gene in 1,912 Queensland 
TABLE I. Parameter Estimates From Segregation Analysis of Cutaneous Melanoma in a Sample of 1,912 Families Ascertained Through Probands Diagnosed With Cutaneous Melanoma in Queensland, 1982-1990*

\begin{tabular}{|c|c|c|c|c|c|c|c|}
\hline \multirow[b]{3}{*}{ Parameter } & \multicolumn{6}{|c|}{ Hypothesis } & \multirow{3}{*}{$\begin{array}{l}\text { Full } \\
\text { model }\end{array}$} \\
\hline & \multicolumn{3}{|c|}{ Medelian inheritance } & \multicolumn{2}{|c|}{ Environmental factors } & \multirow{2}{*}{$\begin{array}{c}\text { No major } \\
\text { type }\end{array}$} & \\
\hline & Dominant & Recessive & Co-dominant & Two groups & Three groups & & \\
\hline $\begin{array}{l}\text { Allele frequency qA } \\
\text { Transmission prob. }\end{array}$ & 0.091 & 0.187 & 0.247 & 0.006 & 0.013 & - & 0.0004 \\
\hline$\tau_{\mathrm{AA}}$ & 1.0 & 1.0 & 1.0 & 0.175 & 0.315 & - & 1.0 \\
\hline$\tau_{\mathrm{AB}}$ & 0.5 & 0.5 & 0.5 & 0.175 & 0.315 & - & 0.74 \\
\hline$\tau_{\mathrm{BB}}$ & 0 & 0 & 0 & 0.175 & 0.315 & - & 0.04 \\
\hline $\begin{array}{l}\text { Age coefficient } \alpha \\
\text { Baseline parameters }\end{array}$ & 0.105 & 0.087 & 0.167 & 0.085 & 0.139 & 0.085 & 0.142 \\
\hline$\beta_{\mathrm{AA}}$ & -4.83 & -4.88 & -5.73 & -5.79 & -5.36 & -5.29 & -4.88 \\
\hline$\beta_{\mathrm{AA}}$ & -4.83 & -9.45 & -10.52 & -5.79 & -9.65 & -5.29 & -9.13 \\
\hline$\beta_{\mathrm{BB}}$ & -8.00 & -9.45 & -15.54 & -34.59 & -63.18 & -5.29 & -16.49 \\
\hline Mean age of onset & 46.05 & 55.76 & 34.18 & 6814 & & & \\
\hline $\begin{array}{l}\mu_{\mathrm{AA}} \\
\mu_{\mathrm{AB}}\end{array}$ & $\begin{array}{l}46.05 \\
46.05\end{array}$ & $\begin{array}{r}55.16 \\
107.95\end{array}$ & $\begin{array}{l}34.18 \\
62.77\end{array}$ & $\begin{array}{l}68.14 \\
68.14\end{array}$ & $\begin{array}{l}38.49 \\
69.27\end{array}$ & $\begin{array}{l}62.16 \\
62.16\end{array}$ & $\begin{array}{l}34.38 \\
64.31\end{array}$ \\
\hline$\mu_{\mathrm{BB}}$ & 76.30 & 107.95 & 92.73 & 406.92 & 453.64 & 62.16 & 116.08 \\
\hline S.D. of age of onset & 17.31 & 20.73 & 10.82 & 21.34 & 13.02 & 21.32 & 12.77 \\
\hline Susceptibility $\gamma$ & 0.116 & 0.436 & 0.113 & 0.630 & 0.330 & 0.093 & 1.0 \\
\hline Additional fam. depend. & & & & & & & \\
\hline$\delta_{\text {parent unaffected }}$ & 0 & 0 & 0 & 0 & 0 & 0 & 0 \\
\hline$\delta_{\text {Parent unaffected }}$ & 0 & 0 & 0 & 0 & 0 & 0 & 0 \\
\hline CI by 100 yrs & 0.109 & 0.155 & 0.098 & 0.008 & 0.008 & 0.090 & 0.093 \\
\hline$-2(\ln \mathrm{L})(\#$ parameters $)$ & $14,607.0(5)$ & $14,567.3(5)$ & $14,426.8(6)$ & $13,754.1(6)$ & $13,736.0(7)$ & $14,758.8(3)$ & $13,060.4(9)$ \\
\hline$\chi^{2}\left(\mathrm{df}^{) \mathrm{a}}\right.$ & $1,546.6(4)$ & $1,507.0(4)$ & $1,366.5(3)$ & $693.7(3)$ & $675.6(2)$ & $1,698.5(6)$ & \\
\hline$P$ value & $<0.001$ & $<0.001$ & $<0.001$ & $<0.001$ & $<0.001$ & $<0.001$ & \\
\hline
\end{tabular}

*In this group of models, there is assumed to be no familial dependence (genetic or environmental) in addition to that explained by Medelian inheritance. Numbers in boldface are independent parameter estimates.

${ }^{\mathrm{a}} \chi^{2}=(-2 \ln \mathrm{L}$ of the data under the hypothesis of interest $)-(-2 \ln \mathrm{L}$ of the data under the full model $)$. 
TABLE II. Parameter Estimates From Segregation Analysis of Cutaneous Melanoma in a Sample of 1,912 Families Ascertained Through Probands Diagnosed With Cutaneous Melanoma in Queensland, 1982-1990*

\begin{tabular}{|c|c|c|c|c|c|c|c|}
\hline \multirow[b]{3}{*}{ Parameter } & \multicolumn{6}{|c|}{ Hypothesis } & \multirow{3}{*}{$\begin{array}{c}\text { Full } \\
\text { model }\end{array}$} \\
\hline & \multicolumn{3}{|c|}{ Mendelian inheritance } & \multicolumn{2}{|c|}{ Environmental factors } & \multirow{2}{*}{$\begin{array}{c}\text { No major } \\
\text { type }\end{array}$} & \\
\hline & Dominant & Recessive & Codominant & Two groups & Three groups & & \\
\hline $\begin{array}{l}\text { Allele frequency } \mathrm{q}_{\mathrm{A}} \\
\text { Transmission prob. }\end{array}$ & 0.005 & 0.076 & 0.001 & 0.006 & 0.007 & - & 0.047 \\
\hline$\tau_{\mathrm{AA}}$ & 1.0 & 1.0 & 1.0 & 0.090 & 0.909 & - & 0.01 \\
\hline$\tau_{\mathrm{AB}}$ & 0.5 & 0.5 & 0.5 & 0.090 & 0.909 & - & $\mathbf{0}$ \\
\hline$\tau_{\mathrm{BB}}$ & 0 & 0 & 0 & 0.090 & 0.909 & - & 1.0 \\
\hline $\begin{array}{l}\text { Age coefficient } \alpha \\
\text { Baseline parameters }\end{array}$ & 0.203 & 0.183 & 0.282 & 0.211 & 0.243 & 0.100 & 0.121 \\
\hline$\beta_{\mathrm{AA}}$ & -12.85 & -12.00 & -11.47 & -13.93 & -21.43 & -9.68 & -11.10 \\
\hline$\beta_{\mathrm{AB}}$ & -12.85 & -18.18 & -18.94 & -13.93 & -15.01 & -9.68 & -15.30 \\
\hline$\beta_{\mathrm{BB}}$ & -18.08 & -18.18 & -25.42 & -20.86 & -28.89 & -9.68 & -19.90 \\
\hline Mean age of onset & & & & & & & \\
\hline$\mu_{\mathrm{AA}}$ & 63.27 & 65.64 & 40.66 & 65.94 & 88.21 & 97.20 & 91.92 \\
\hline$\mu_{\mathrm{AB}}$ & 63.27 & 99.40 & 67.12 & 65.94 & 61.79 & 97.20 & 126.73 \\
\hline$\mu_{\mathrm{BB}}$ & 88.98 & 99.40 & 90.09 & 98.74 & 118.95 & 97.20 & 164.77 \\
\hline S.D. of age of onset & 8.93 & 9.92 & 6.43 & 8.59 & 7.47 & 18.21 & 15.03 \\
\hline $\begin{array}{l}\text { Susceptibility } \gamma \\
\text { Additional fam. depend }\end{array}$ & 0.221 & 0.567 & 0.217 & 0.494 & 0.407 & 0.401 & 0.720 \\
\hline$\delta_{\text {parent unaffected }}$ & $\mathbf{0}$ & $\mathbf{0}$ & $\mathbf{0}$ & $\mathbf{0}$ & $\mathbf{0}$ & $\mathbf{0}$ & $\mathbf{0}$ \\
\hline$\delta_{\text {parent affected }}$ & 6.56 & 6.79 & 9.97 & 6.94 & 7.18 & 3.81 & 7.70 \\
\hline CI by 100 yrs & 0.200 & 0.301 & 0.205 & 0.282 & 0.010 & 0.228 & 0.004 \\
\hline-2 (ln L) \# parameters) & $12,717.6(7)$ & $12,499.6(7)$ & $12,181.6(8)$ & $12,508.6(8)$ & $12,234.3(9)$ & $13,288.2(5)$ & $11,047.6(11)$ \\
\hline$\chi^{2}(\mathrm{df})^{\mathrm{a}}$ & $1,670.0(4)$ & $1,452.0(4)$ & $1,134.1(3)$ & $1,461.0(3)$ & $1,186.8(2)$ & $2,240.6(6)$ & \\
\hline$P$ value & $<0.001$ & $<0.001$ & $<0.001$ & $<0.001$ & $<0.001$ & $<0.001$ & \\
\hline
\end{tabular}

*In this group of models, there is assumed to be familial dependence (genetic or environmental) in addition to that explained by Mendelian inheritance. Numbers in bold face are independent parameter estimates.

${ }^{\mathrm{a}} \chi^{2}=(-2 \ln \mathrm{L}$ of the data under the hypothesis of interest $)-(-2 \ln \mathrm{L}$ of the data under the full model $)$. 
Aitken et al.

families ascertained through probands with a recent diagnosis of melanoma. The following broad groups of hypotheses were investigated to explain the familial occurrence of melanoma: (1) Mendelian transmission of a single major gene with two alleles, with no additional familial dependence, (2) a major, randomly distributed, environmental factor, producing either two or three age-of-onset distributions in the population, with no familial dependence, (3) Mendelian transmission of a single major gene with two alleles, with additional familial dependence, and (4) a major, randomly distributed, environmental factor with, in addition, familial dependence due to unexplained shared environmental or genetic factors. All four groups of hypotheses were rejected.

Our results are in agreement with those of Speer et al. [1992] who found no evidence for segregation of a major gene for melanoma in a group of Utah families, some of whom were ascertained through clusters of melanoma cases and some through random sampling of clinic cases selected independently of family history. This is in contrast to most other segregation analyses of melanoma, which have supported Mendelian transmission of a major gene as the basis for the familial clustering of this disease. Greene and colleagues [1983] investigated 14 families with two or more living members with cutaneous malignant melanoma ascertained through a Cancer Family Register. Using the Elston-Stewart maximum likelihood method of segregation analysis, they found that the distribution of melanoma in these kindreds was consistent with autosomal dominant inheritance of a single susceptibility gene. Based on life table and disease-free survival analysis in the same 14 kindreds, Bale and colleagues [1986] demonstrated an autosomal dominant mode of inheritance for the combined phenotype of melanoma/dysplastic nevus syndrome in which relatives were considered affected if they had either melanoma or histologically verified dysplastic nevi. Lynch et al. [1983] and Bergman et al. [1986] presented segregation analyses whose results also suggested autosomal dominant inheritance of the combined malignant melanoma/dysplastic nevus syndrome. Most analyses supporting the major gene hypothesis have been based on small numbers of highly selected families with a strong history of melanoma and multiple dysplastic nevi and as such are likely to present a more genetically homogeneous sample than that analysed here.

As far as we are aware, ours is the first segregation analysis of families ascertained through a population-based sample of melanoma cases. We have demonstrated significant heterogeneity in melanoma risk between these families [Aitken et al., 1994]. After accounting for family size and the sex, ages, and birth cohorts of relatives, $\sim 5 \%$ of our families have a very strong melanoma history, often diagnosed at a young age, suggestive of inherited susceptibility [Aitken et al., 1994]. (After adjusting for our weighted sampling scheme, this corresponds to $<1 \%$ of the families of melanoma cases in the total Queensland population). The remaining families have only one or two affected members and appear to be at much lower genetic risk. Queensland has the world's highest recorded incidence of melanoma, the result of a white-skinned population residing in a subtropical climate with high levels of solar radiation. Although the causes of melanoma are complex and include both genetic and environmental components, it is likely that environment plays the major role in many, if not most, of the cases in our low familial risk kindreds. Although a major gene may be segregating in our high risk families, this effect may have been masked in a background of such high apparently sporadic incidence. 
It is also possible that the assumptions underlying segregation analysis are not appropriate in this situation, in particular, the assumption that Mendelian transmission, if it exists, is through a single major gene with two alleles. The melanoma susceptibility gene CDKN2A identified on chromosome 9p21 appears to be inherited in dominant Mendelian fashion. Although the proportion of familial melanoma attributable to this gene is unknown, it is clear that many melanoma kindreds exist that do not carry germline mutations in CDKN2A [Kamb et al., 1994b; Platz et al., 1997]. Further, there is some evidence for genetic heterogeneity in melanoma inheritance [Goldstein et al., 1994; MacGeoch et al., 1994]. Whereas familial melanoma has most commonly been linked to chromosome 9p in North American [CannonAlbright et al., 1992; Hussussian et al., 1994; Kamb et al., 1994b], Dutch [Gruis et al., 1995], Australian [Nancarrow et al., 1993], and British [MacGeoch et al., 1994] families, linkage to chromosome $1 \mathrm{p}$ and $6 \mathrm{p}$ also have been reported [Goldstein et al., 1993; Walker et al., 1994]. If two or more major genes are segregating in our sample with different modes of inheritance, the results of segregation analysis become extremely difficult to interpret.

In conclusion, using a population-based sample of families ascertained through melanoma cases, we have demonstrated familial transmission of malignant melanoma that cannot be explained by Mendelian inheritance of a single major gene. We have collected proxy- or self-reported melanoma risk factors for $61 \%$ of relatives, including counts of nevi on the arm and back, pigmentation characteristics, ability to suntan, propensity to sunburn, and an approximate lifetime history of sun exposure [described in detail in Aitken et al., 1996a]. In future segregation analyses, the inclusion of relatives' risk factors in the models may reveal whether all or a combination of these explains the familial dependence that we have clearly demonstrated. If a major gene exists that operates independently of these covariates, including them in the models may reduce residual variation and increase the power of the analysis to detect a major gene effect, as has been observed for lung cancer when the inclusion of information on smoking increased the power for detecting a major gene for this disease [Sellers et al., 1990].

\section{ACKNOWLEDGMENTS}

This work was supported by National Health and Medical Research Council project grants 870774, 900536, and 930223, and a Queensland Cancer Fund research grant.

\section{REFERENCES}

Aitken JF, Duffy DL, Green A, et al. (1994): Heterogeneity of melanoma risk in families of melanoma patients. Am J Epidemiol 140:961-973.

Aitken JF, Green AC, MacLennan R, et al. (1996a): The Queensland Familial Melanoma Project: Study design and characteristics of participants. Melanoma Res 6:155-165.

Aitken JF, Youl P, Green AC, et al. (1996b): Accuracy of case-reported family history of melanoma in Queensland, Australia. Melanoma Res 6:313-317.

Bailey-Wilson JE, Elston RC, Schuelke GS, et al. (1986): Segregation analysis of hereditary nonpolyposis colorectal cancer. Genet Epidemiol 3:27-38.

Bale S, Chakravarti A, Greene MH (1986): Cutaneous malignant melanoma and familial dysplastic nevi: Evidence for autosomal dominance and pleiotropy. Am J Hum Genet 38:188-196. 


\section{$400 \quad$ Aitken et al.}

Bergman W, Palan A, Went LN (1986): Clinical and genetic studies in six Dutch kindreds with the dysplastic nevus syndrome. Ann Hum Genet 50:249-258.

Bonney GE (1986): Regressive logistic models for familial disease and other binary traits. Biometrics 42:611-625.

Cannings C, Thompson EA (1977): Ascertainment in the sequential sampling of pedigrees. Clin Genet 12:208-212.

Cannon-Albright LA, Goldgar DE, Meyer LJ, et al. (1992): Assignment of a locus for familial melanoma, MLM, to chromosome 9p13-22. Science 258:1148-1152.

Elston RC, Stewart J (1971): A general model for the genetic analysis of pedigree data. Hum Hered 21:523-542.

Go RCP, King MC, Bailey-Wilson J, et al. (1993): Genetic epidemiology of breast cancer and associated cancers in high-risk families. I. Segregation analysis. JNCI 70:455-461.

Goldstein AM, Dracopoli NC, Ho EC, et al. (1993): Further evidence for a locus for cutaneous malignant melanoma-dysplastic naevus $(\mathrm{CMM} / \mathrm{DN})$ on chromosome $1 \mathrm{p}$, and evidence for genetic heterogeneity. Am J Hum Genet 52:537-550.

Goldstein AM, Dracopoli NC, Engelstein M, et al. (1994): Linkage of cutaneous malignant melanoma/ dysplastic nevi to chromosome 9p, and evidence for genetic heterogeneity. Am J Hum Genet 54:489-496.

Goldstein AM, Goldin LR, Dracopoli NC, et al. (1996): Two-locus linkage analysis of cutaneous malignant melanoma/dysplastic nevi. Am J Hum Genet 58:1050-1056.

Green A, Bain C, MacLennan R, et al. (1986): Risk factors for cutaneous melanoma in Queensland. In Gallagher RP (ed): "Recent Results in Cancer Research.” Berlin: Springer-Verlag, pp 76-97.

Greene MH, Goldin LR, Clark WH, et al. (1983): Familial cutaneous malignant melanoma: Autosomal dominant trait possibly linked to the $R h$ locus. Proc Natl Acad Sci 80:6071-6075.

Gruis NA, Sandkuijl LA, van der Velden PA, et al. (1995): CDKN2 explains part of the clinical phenotype in Dutch familial atypical multiple-mole melanoma (FAMMM) syndrome families. Melanoma Res 5:169-177.

Holman CDJ, Armstrong BK (1984): Pigmentary traits, ethnic origin, benign nevi and family history as risk factors for cutaneous malignant melanoma. J Natl Cancer Inst 72:257-266.

Hopper JL, Carlin JB (1992): Familial aggregation of a disease consequent upon correlation between relatives in a risk factor measured on a continuous scale. Am J Epidemiol 136:1138-1147.

Hussussian CJ, Struewing JP, Goldstein AM, et al. (1994): Germline p16 mutations in familial melanoma. Nature Genet 8:15-21.

I.A.R.C. (1992): Monographs on the evaluation of carcinogenic risks to humans. Vol. 55, "Solar and Ultraviolet Radiation.” Lyon: I.A.R.C.

Kamb A, Gruis NA, Weaver-Feldhaus J, et al. (1994a): A cell cycle regulator potentially involved in genesis of many tumor types. Science 264:436-440.

Kamb A, Shattuck-Eidens D, Eeles R, et al. (1994b): Analysis of the p16 gene (CDKN2) as a candidate for the chromosome 9p melanoma susceptibility locus. Nature Genet 8:22-26.

Kleinbaum DG, Kupper LL, Morgenstern H (1982): "Epidemiologic Research.” London: Lifetime Learning, p 431.

Lynch HT, Fusaro RM, Kimberling WJ, et al. (1983): Familial atypical multiple mole-melanoma (FAMMM) syndrome: segregation analysis. J Med Genet 20:342-344.

MacGeoch C, Newton Bishop JA, Bataille V, et al. (1994): Genetic heterogeneity in familial malignant melanoma. Hum Mol Genet 3:2195-2200.

MacLennan R, Green AC, McLeod GRC, et al. (1992): Increasing incidence of cutaneous melanoma in Queensland, Australia. J Natl Cancer Inst 84:1427-1432.

Nancarrow DJ, Mann GJ, Holland EA, et al. (1993): Confirmation of chromosome 9p linkage in familial melanoma. Am J Hum Genet 53:936-942.

Platz A, Hansson J, Månsson-Brahme E, et al. (1997): Screening of germline mutations in the CDKN2A and CDKN2B genes in Swedish families with hereditary cutaneous melanoma. J Natl Cancer Inst 89:697-702.

S.A.G.E. Statistical Analysis for Genetic Epidemiology, Release 2.1 (1992): Computer program package available from the Department of Epidemiology and Biostatistics, Case Western Reserve University, Cleveland, $\mathrm{OH}$. 
Sellers TA, Bailey-Wilson JE, Elston RC, et al. (1990): Evidence for Mendelian inheritance in the pathogenesis of lung cancer. J Natl Cancer Inst 82:1272-1279.

Speer MC, Haynes CS, Pericak-Vance MA (1992): Segregation analysis in cutaneous malignant melanoma/dysplastic nevus syndrome families. Cytogenet Cell Genet 59:225-227.

Walker GJ, Nancarrow DJ, Walters MK, et al. (1994): Linkage analysis in familial melanoma kindreds to markers on chromosome 6p. Int J Cancer 59:771-775.

Walker GJ, Hussussian CJ, Flores JF, et al. (1995): Mutations of the CDKN2/p16 ${ }^{\mathrm{INK} 4}$ gene in Australian melanoma kindreds. Hum Mol Genet 4:1845-1852.

Wallace DC, Exton LA, McLeod GRC (1971): Genetic factors in malignant melanoma. Cancer 27:1262-1266. 